أثر الثراكة المصرية في التكتلات الاقتصادية والاتفاقيات الثنائية على الصادرات الزراعية

عادل يوسف عوض، مجدي محمد الجندي، رجب مغاوري علي زين، هاجر محمد قتديل

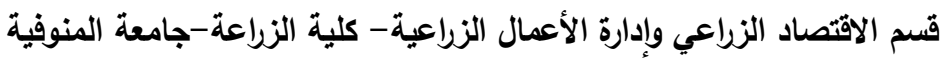

Received: Jun. 29, 2021

Accepted: Jul. 8, 2021

الملخص

استهدفت الاراسة الإجابة على ثلاثة تساؤلات الأول منها يبحث في اختلاف حجم الصادرات الزراعية المصرية بين

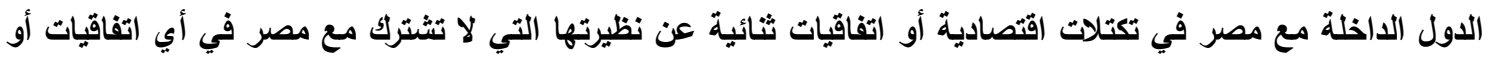

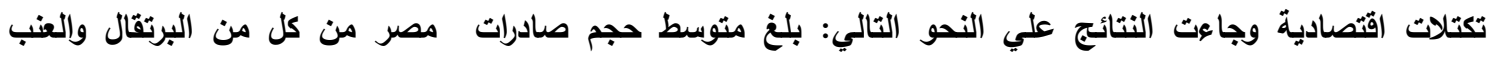

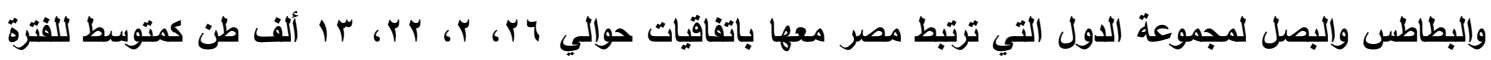

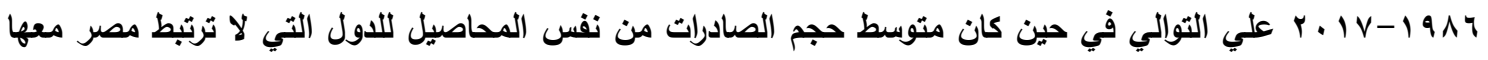

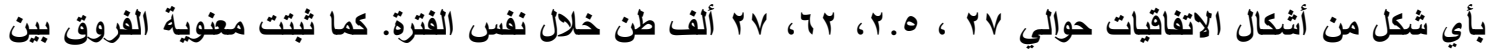

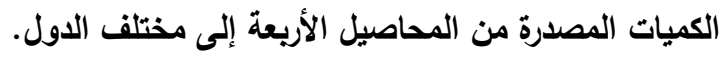

ويالانتقال إلى التساؤل الثاني والذي يعكس أثر تفعيل الاتفاقيات التجارية أو التكتلات على تغير حجم الصادرات من

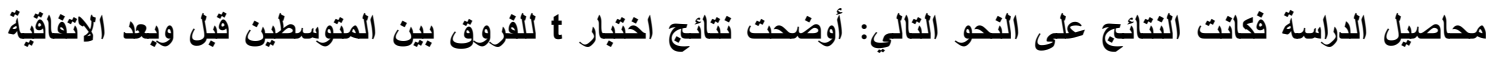
ثبوت معنويه جميع الفروق بين متوسط الصادرات من البرتقال المصري بعد وقبل تفعيل الاتفاقيات بين الدول المشار إليها

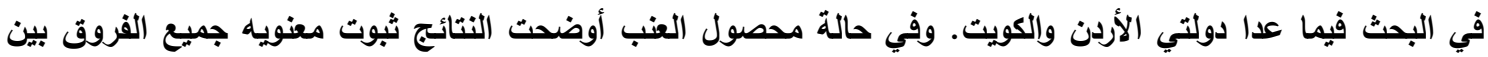

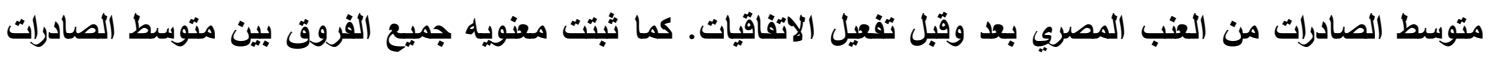

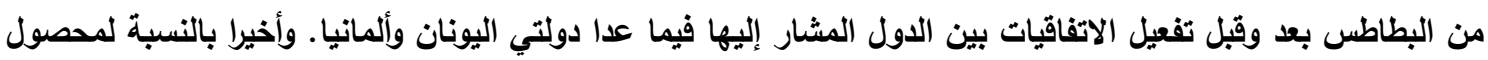
البصل أثثارت النتائج إلى ثبوت معنوية جميع الفروق بين متوسط الصادرات من البصل المصري بعد وقبل تفعيل الاتفاقيات من الدول المشار إليها في الدراسة فيما عدا دولتي الكويت واليونان.

وأخيرا بالنسبة للتساؤل الثالث الأي يبحث في أثر تفعيل الاتفاقيات على سلوك الصادرات الزراعية إلى الاول المشاركة مع مصر في اتفاقيات تجارية فقط تبين ثبوت معنوية نموذج دالة الانحدار بصفة عامة بالنسبة للأربع محاصيل سواء كاتت هذه المعنوية في مقطع الدالة فقط أو الميل فقط أو كلاهما معا.

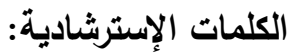

في جميع مناطق العالم، لارجة يندر معها أن توجد دولة

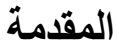

ليست عضوا في تكتل اقتصادي معين. ومن بين التكتلات

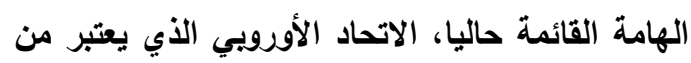

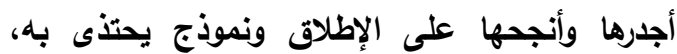

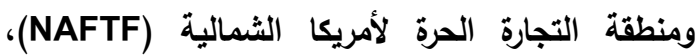
ومنتدى التعاون الاقتصادي لدول آسيا والمحيط الهادي

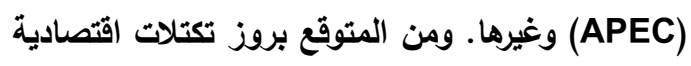

شهر العالم عدة تطورات وتحولات عميقة في بنية

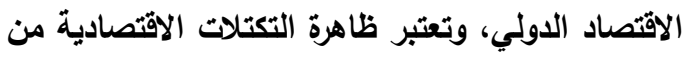
أكثر الظواهر العالمية اللافتة للانتباه، وخاصة بعد انتقال

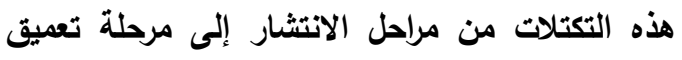

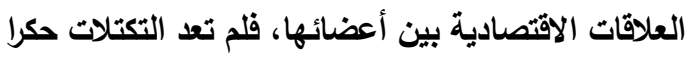
على قارة أو مجموعة دول أو إقليم بعينه، وإنما انتشرت 
A. Awad, et al.,

\section{الطريقة البحثية}

للإجابة على تساؤلات البحث فقد تم استخدام أسلوب البولئ

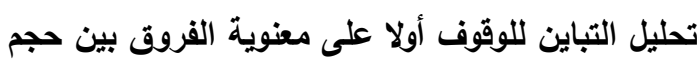

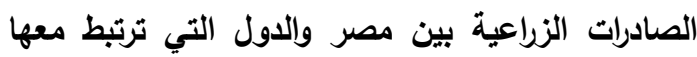

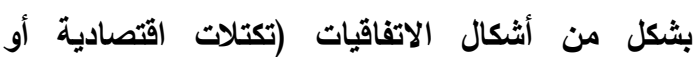
اتفاقيات ثنائية) وتلك الدول التي لاتئت الترتبط معها بأي شكل

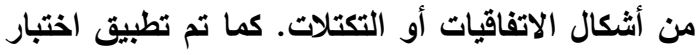
(t) للفروق بين المتوسطين (قبل ويعد الاتفاقية)، وللإجابة على التساؤل الثالث والخاص بمدى تغير سلوك الصادرات من محاصيل البحث إلى الدول التي ترتبط بها مصر من خلال أي شكل من أشكال الاتفاقيات التجارية

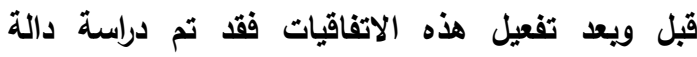

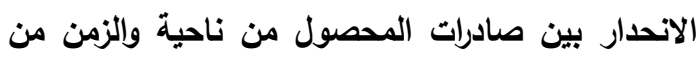

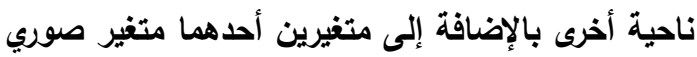

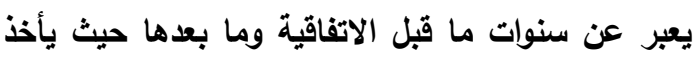

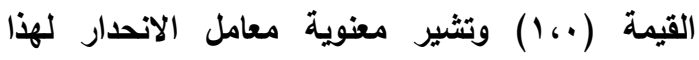

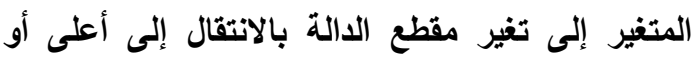

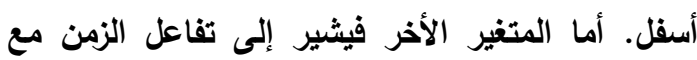
الاتفاقية وثبوت معنوية ميل هذا المتغير يشير إلى تغير

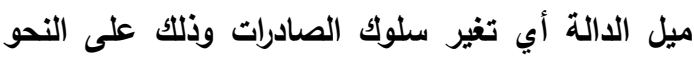
المبين بالنموذج التالي:

$$
y_{i t}=\alpha+B_{1} x_{t}+B_{2} D+B_{3} D X_{t}
$$

حيث:

i تثير إلي كمية الصادرات في السنة

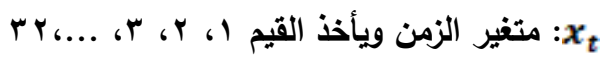
تمتغير انتقالي يأخذ القيمة (صفر) في السنوات قبل

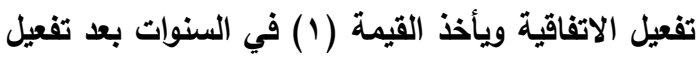

الاتفاقية

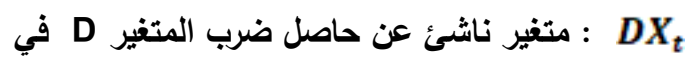

$$
\text { المتغير }
$$
年 $\alpha_{,}, B_{1}, B_{2}, B_{3}$

$$
\text { مصادر البيانات }
$$

اعتمد البحث على البيانات المنشورة خلال الفترة  الطازجة، والبصل الطازج، والمنشورة على قواعد بيانات
أخرى في المرحلة القادمة، كما تعددت دوافع إقامة هذه

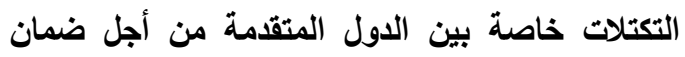

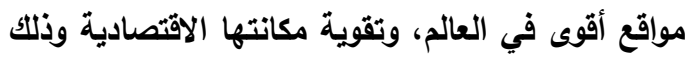
بمنظق المصالح المشتركة. وسوف يتم تناول أثر الشراكة المصرية في التكتلات الاقتصادية والاتفاقيات الثنائية على صادرات مصر من البرتقال، والعنب، والبطاطس،

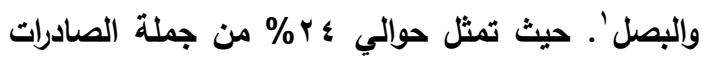

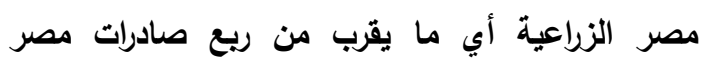

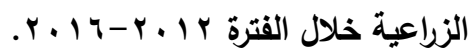
مشكلة البحث تم عرض مشكلة البحث من خلال عدة تساؤلات وهي: هل كان لشراكة مصر في التكتلات الاقتصادية

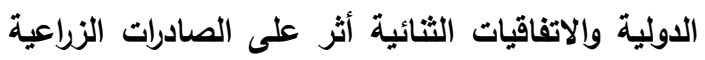
المصرية. ويمغنى آخر هل حجم الصادرات الزراعية المصرية يختلف بين الدول الداخلة مع مصر في تكتلات اقتصادية أو تلك الدول التي بينها وبين مصر اتفاقيات ثنائية عن نظيرتها التي لا تثترك معها مصر في أي الي اتفاقيات أو تكتلات؟ هذا من ناحية، ومن ناحية أخرى

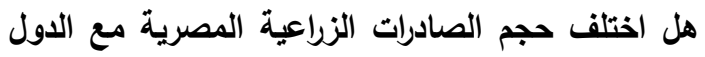
التي ترتبط معها مصر بأي شكل من أثنكال الاتفاقيات

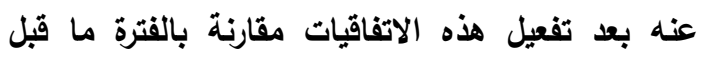

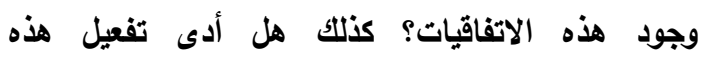
الاتفاقيات إلى تغير سلوك الصادرات إلى الدول المشاركة

$$
\text { مع مصر في اتفاقيات تجارية. }
$$

$$
\text { هدف البحث }
$$

يستهدف البحث دراسة وتحديد أثر شراكة مصر في

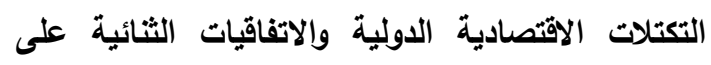

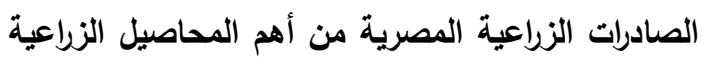
(البرتقال، والعنب، والبطاطس الطازجة، والبصل الطازج)، ويمغني آخر فإن هذف البحث يتلخص في الإجابة على البى الأسئلة التي تم تناولها في المشكلة البحثية.

ـ ' تمثل أهم صادرات مصر من مجمو عة الفاكهة ومحاصيل 


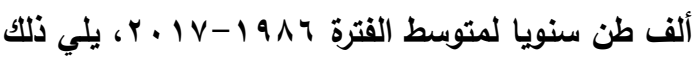
إنجلترا بنحو ^^ ألف طن ثم هولندا وأوكراتيا بصادرات

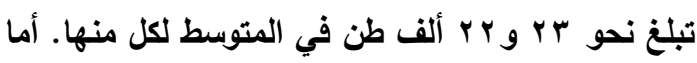
بالنسبة لصادرات البرتقال إلى الدول خارج الاتفاقيات فكانت روسيا الاتحادية أهم مستورد للبرتقال المصري بكمية تصل إلى 19 ألف طن سنويا في متوسط نفس الاديه الفترة، يلي ذلك كل من الهند وهونج كونج وماليزيا بكميات تزيد قليلا عن ج آلاف طن لكل منهر. ويلغ متوسط حجم الصادرات من البرتقال لمجموعة

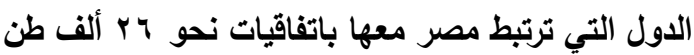

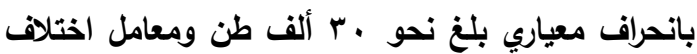

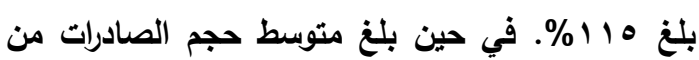
البرتقال للاول التي لا ترتبط مصر معها بأي شكل من فن

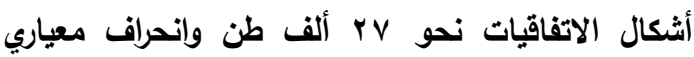
يقدر بنحو ·r ألف طن، وقد بلغ معامل الاختلاف لهذه

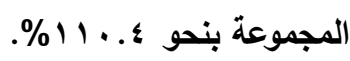

منظمة الأغذية والزراعة (الفاو)، كما تم الاستعانة

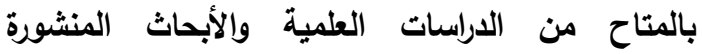
والمرتبطة بموضوع البحث سواء بالدوريات المطبوعة أو من خلال المواقع الإلكترونية لبنت المعرفة المصري واتحاد مكتبات الجامعات المصرية. النتائج والمناقشات

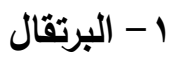

1-1 أثر وجود الاتفاقيات التجارية على حجم الصادرات من البرتقال المصري

يبين الجدول (1) أهم الدول المستوردة للبرتقال المصري والتي ترتبط مصر معها بشكل ما من أثكال

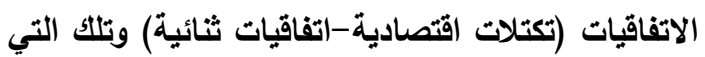
لا ترتبط بها مصر بأي اتفاقيات، حيث يتبين أن السعودية هي أهم مستورد للبرتقال المصري من بين الدول التي ترتبط بها مصر من خلال الاتفاقيات

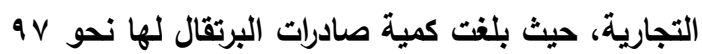

\begin{tabular}{|c|c|c|c|c|}
\hline معامل الاختلاف (\%) & الانحراف المعياري & 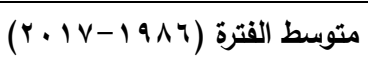 & الدولة & \\
\hline \multirow{9}{*}{114.9} & 94.43 & 96.98 & السعودية & \multirow{9}{*}{$\begin{array}{l}3 \\
\overline{3} \\
\text { 行 } \\
\text { 哥 }\end{array}$} \\
\hline & 23.14 & 27.67 & إنجلترا & \\
\hline & 30.89 & 22.54 & هولندا & \\
\hline & 29.25 & 22.04 & أوكرانيا & \\
\hline & 28.63 & 14.53 & الإمارات & \\
\hline & 8.99 & 8.98 & عمان & \\
\hline & 11.31 & 8.91 & الأردن & \\
\hline & 15.27 & 8.87 & 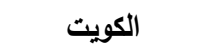 & \\
\hline & 30.24 & 26.31 & المتوسط & \\
\hline \multirow{5}{*}{110.4} & 87.73 & 91.04 & روسيا الاتحادية & \multirow{5}{*}{ 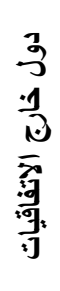 } \\
\hline & 13.94 & 6.44 & الهند & \\
\hline & 9.90 & 6.16 & هونج كونج & \\
\hline & 9.57 & 6.13 & 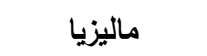 & \\
\hline & 30.28 & 27.44 & المتوسط & \\
\hline
\end{tabular}

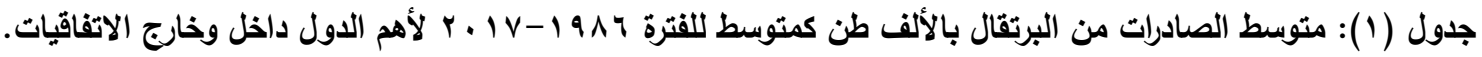

www.fao.org المصدر : جمعت وحسبت من قاعدة بيانات موقع منظمة الأغذية والزراعة 
ويعد الاتفاقية) أتت النتائج على النحو المبين بالجدول

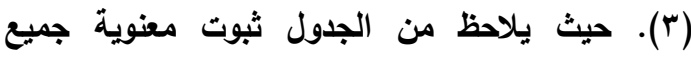
الفروق بين متوسط الصادرات من البرتقال المصري بعد وقبل تفعيل الاتفاقيات بين الدول المشار إليها بالجدول السابق فيما عدا دولتي الأردن والكويت والذي يمكن تفسيره من خلال حجم التغير في الصادرات بين الفترتين. هذا وتفسر المعنوية بين الفترتين من خلال زيادة متوسط الصادرات بشكل واضح من البرتقال المصري بعد تفعيل الاتفاقيات بين مصر ومجموعة الدول المشار إليها

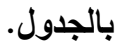

ويإجراء تحليل التباين أحادي الاتجاه لصادرات مصر

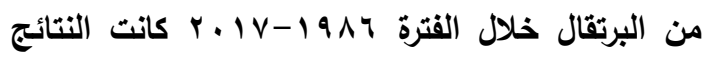
على النحو المبين بالجدول (r) حيث يبين الجدول تحليل التباين ثبوت معنوية الفروق بين الكميات المصدرة من

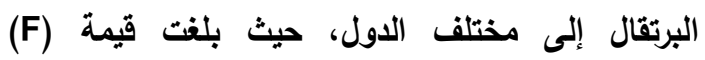

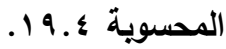

ا - أثر تفعيل الاتفاقيات التجارية على تغير حجم الصادرات من البرتقال المصري

بتطبيق اختبار (t) للفروق بين المتوسطين (قبل

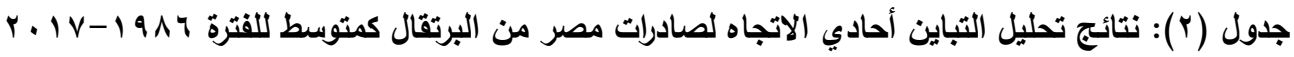

\begin{tabular}{|c|c|c|c|c|c|}
\hline المعنوية & المحسوية F & متوسط مجموع المريعات & مجموع المريعات & درجات الحرية & مصدر التباين \\
\hline \multirow{3}{*}{0.000} & \multirow{3}{*}{19.4} & 33368.5 & 367053.7 & 11.0 & بين الدول \\
\hline & & 1717.1 & 638765.3 & 372.0 & داخل الدول \\
\hline & & & 1005819.1 & 383.0 & الكلي \\
\hline
\end{tabular}

www.fao.org المصدر: جمعت وحسبت من قاعدة بيانات موقع منظمة الأغذية والزراعة

جدول (r): اختبار (t) لبيان أثر الاتفاقيات مع دول الاتفاقيات (قبل ويعد الاتفاقية) لصادرات مصر من البرتقال كمتوسط

\begin{tabular}{|c|c|c|c|c|c|}
\hline \multicolumn{6}{|c|}{ 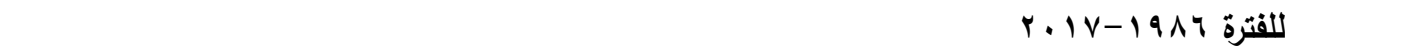 } \\
\hline الاتفاقيطة بعد & المتوسط قبل & قيمة (t) المحسوية & عدد سنوات ما بعد & عدد سنوات ما قبل & الاتفاقيات \\
\hline 149.95 & 8.69 & $\begin{array}{l}-5.95 * * \\
-7.65 * *\end{array}$ & 20 & 12 & السعودية \\
\hline 51.54 & 9.10 & $\begin{array}{l}-13.28 * * \\
-12.20 \% *\end{array}$ & 14 & 18 & إنجلترا \\
\hline 48.58 & 2.28 & $\begin{array}{l}-6.31 * * \\
-5.55 * *\end{array}$ & 14 & 18 & هولتدا \\
\hline 27.12 & 0.000 & $\begin{array}{l}-2.17 * * \\
-4.57 * * \\
\end{array}$ & 26 & 6 & أوكرانيا \\
\hline 23.5 & 0.00 & $\begin{array}{l}-2.39 * * \\
-3.10 * * \\
\end{array}$ & 20 & 12 & الإمارات \\
\hline 14.30 & 0.12 & $\begin{array}{l}-6.74 * * \\
-8.76 * *\end{array}$ & 20 & 12 & عمان \\
\hline 7.56 & 11.16 & $\begin{array}{l}(0.87)^{* * *} \\
(0.76)^{* * *}\end{array}$ & 20 & 12 & الأردن \\
\hline 11.50 & 4.49 & $\begin{array}{l}(-1.27) \\
(-1.60)\end{array}$ & 20 & 12 & الكويت \\
\hline
\end{tabular}

www.fao.org المصدر: جمعت وحسبت من قاعدة بيانات موقع منظمة الأغذية والززراعة

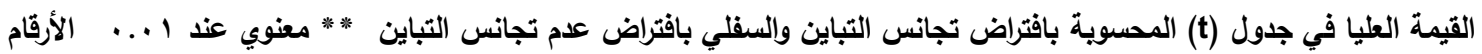
بين الأقواس غير معنوية 
سنويا بعد أن كان حوالى \.. الاتفاقية.

أما في حالة هولندا فقد حدث تغير في مقطع الدالة

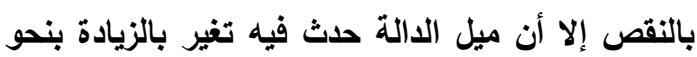

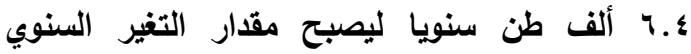
للصادرات من البرتقال المصري إلى هولتدا حوالي بـ.

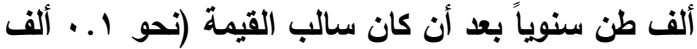
طن). وفى حالة دولة الإمارات العربية المتحدة فقد

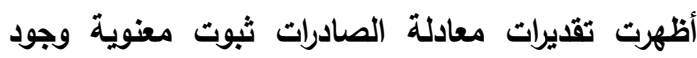

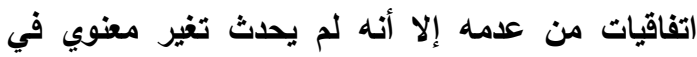
سلوك دالة الصادرات، أو بعبارة أخري لم يحدث تغير معنوي في ميل الدالة نتيجة تفعيل الاتفاقيات التجارية بين مصر والإمارات. ويالنسبة لسلطنة عمان فتشير فئه

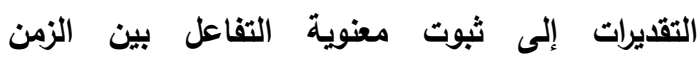
والاتفاقيات حيث تثبر التقديرات إلى زيادة ميل الدالة بنحو ^.. ألف طن ليصبح مقار التغير السنوي

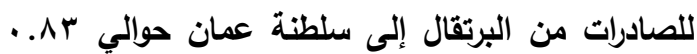

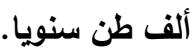

1-r أثر تفعيل الاتفاقيات على تغير سلوك الاتجاه العام لصادرات البرتقال المصري ويتقدير دوال اندار صادرات البرتقال المصري للاول موضع البحث المشاركة مع مصر في اتفاقيات تم

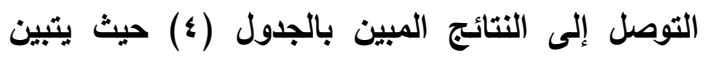

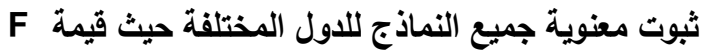
المحسوية للنموذج تزيد عن نظيرتها الجدولية عند

$$
\text { مستوى معنوية ال.... }
$$

وعلى الرغم من ثبوت معنوية النموذج بصفة عامة إلا أن بعض الدول لم تثبت معنوية التغير في الصادرات قبل أو بعد تفعيل الاتفاقيات كما هو الحال في السعودية

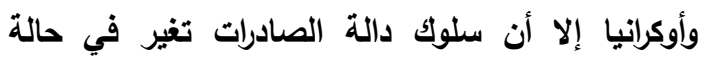
إنجلترا حيث ثبتت معنوية المتغير الأي يعكس تفاعل الأل

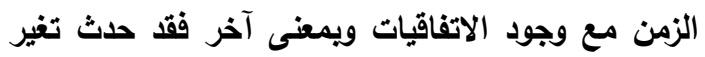

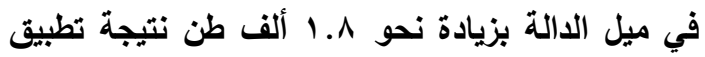
الاتفاقية بين مصر وإنجلترا ليصبح مقدار التغير السنوي

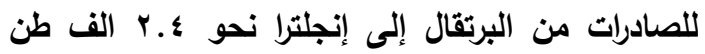

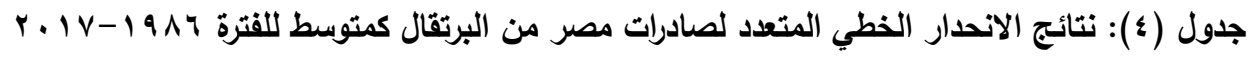

\begin{tabular}{|c|c|c|c|c|}
\hline F المحسوية F & $\hat{R}^{2}$ & $R^{2}$ & المعادلة & الدولة \\
\hline 13.27 & 0.54 & 0.59 & $\begin{aligned} y_{t}= & 24.1-2.4 x_{t}+31.0 D+6.6 D X_{t} \\
& (0.61) \quad(-0.44)(0.45)(1.12)\end{aligned}$ & السعودية \\
\hline 159.62 & 0.94 & 0.95 & 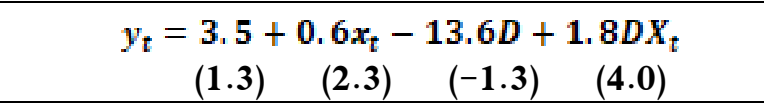 & إنجلترا \\
\hline 66.07 & 0.86 & 0.88 & $\begin{aligned} y_{t}= & 3.2-0.1 x_{t}-115.3 D+6.4 D X_{t} \\
& (0.6)(-0.2)(-5.7) \quad(7.0)\end{aligned}$ & هولندا \\
\hline 11.29 & 0.50 & 0.55 & 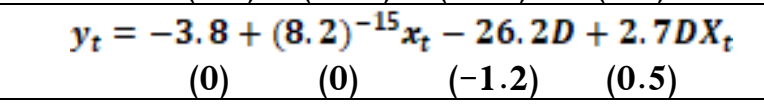 & أوكرانيا \\
\hline 7.51 & 0.39 & 0.45 & $\begin{array}{c}y_{t}=(1.3)^{-13}-(1.9)^{-14} x_{t}-51.2 D+3.3 D X_{t} \\
(0) \quad(0)(-2.1)\end{array}$ & الإمارات \\
\hline 36.5 & 0.78 & 0.80 & $\begin{array}{c}y_{t}=-0.10+0.03 x_{t}-4.8 D+0.8 D X_{t} \\
(-0.03)(0.09)(-1.03)\end{array}$ & عمان \\
\hline 5.98 & 0.33 & 0.39 & $\begin{array}{c}y_{t}=20.7-1.5 x_{t}-42.6 D+2.8 D X_{t} \\
(3.6) \quad(-1.9)(-4.2) \quad(3.2)\end{array}$ & الأردن \\
\hline 8.28 & 0.41 & 0.47 & $\begin{array}{c}y_{t}=-2.7+1.1 x_{t}-32.4 D+1.0 D X_{t} \\
(-0.4) \quad(1.1)(-2.5)(0.89)\end{array}$ & الكويت \\
\hline
\end{tabular}

المصدر : جمعت وحسبت من قاعدة بيانات موقع منظمة الأغذية والزراعة

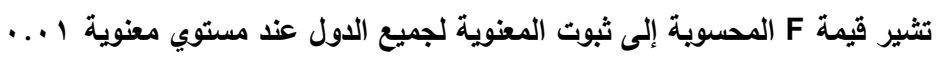


لا ترتبط بها مصر بأي اتفاقيات، حيث يتبين من الجدول أن إنجلترا هي أهم مستورد للعب المصري بهري من بين الدول

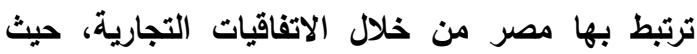
بلغت كمية صادرات العب لها نحو V ألاف طن سنويا

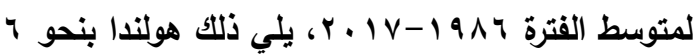

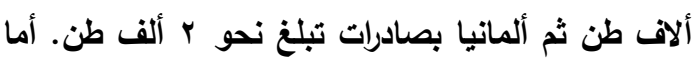

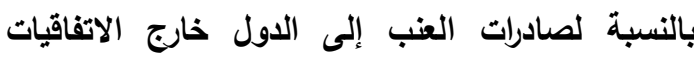

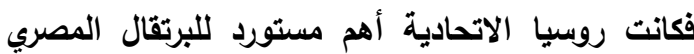

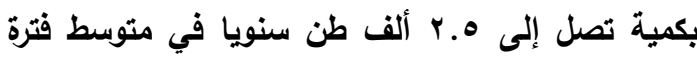

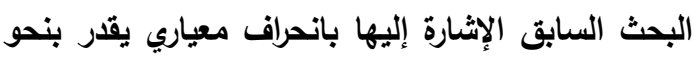
ع ألف ومعامل اختلاف بلغ بنحو $10 V$ V

ويحساب متوسط حجم الصادرات من العب لمجموعة

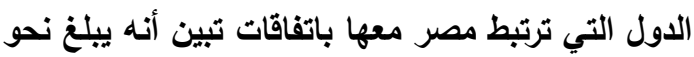

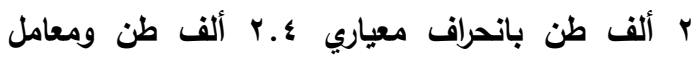

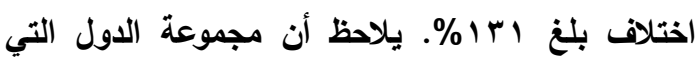
ترتبط مصر معها باتفاقيات كانت أكثر تجانس في لاهي

وارداتها من العنب المصري مقارنة بروسيا الاتحادية.
وفى حالة الأردن تبين ثبوت معنوية كل من المتغير

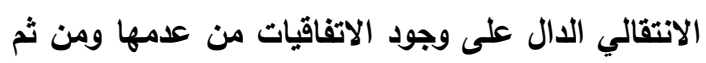
حدوث تغير في مقطع الدالة كنلك تبين ثبوت معنوية التغير في ميل الادالة حيث حدث تغير في الميل يُقدر بنحو ب. r ألف طن ليصبح مقار التغير السنوي

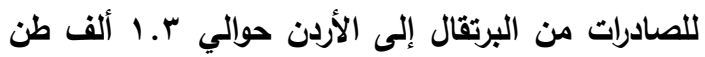
سنويا بعد أن كان سالب الإثارة في سنوات ما قبل تلفيل تلفيل الاتفاقيات. وأخيراً في حالة الكويت تبين فقط معنوية تغير مقطع الالة في حين لم تثبت معنوية التغير في الميل أو معامل الزمن والجدول التالي يلخص النتائج التي تم التواصل إليها.

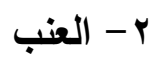
ץ-1 أثر وجود الاتفاقيات التجارية على حجم صادرات مصر من العنب ويعكس الجدول (0) أهم الدول المستوردة للعنب المصري والتي ترتبط مصر معها بشكل ما من أثنكال الاتفاقيات (تكتلات اقتصادية-|تفاقيات ثنائية) وتلكك التي من

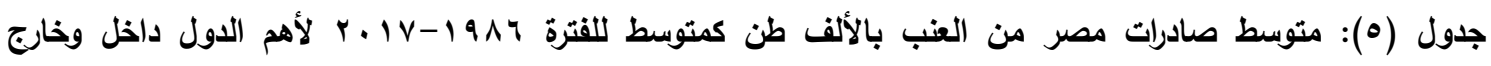

\begin{tabular}{|c|c|c|c|}
\hline \multicolumn{4}{|c|}{ دول الاتفاقيات } \\
\hline معامل الاختلاف (\%) & الانحراف المعياري & متوسط الفترة (Y) & الادولة \\
\hline \multirow{12}{*}{130.72} & 7.45 & 7.22 & إنجلترا \\
\hline & 6.84 & 5.75 & هولندا \\
\hline & 2.49 & 1.89 & ألمانيا \\
\hline & 1.54 & 1.14 & إيطاليا \\
\hline & 0.88 & 0.69 & 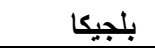 \\
\hline & 1.41 & 0.71 & السعودية \\
\hline & 1.56 & 0.62 & سلوفانيا \\
\hline & 1.59 & 0.68 & الإمارات \\
\hline & 1.12 & 0.55 & الكويت \\
\hline & 0.61 & 0.49 & النرويج \\
\hline & 0.76 & 0.35 & عمان \\
\hline & 2.39 & 1.83 & المتوسط \\
\hline \multicolumn{4}{|c|}{ دول خارج الاتفاقيات } \\
\hline 156.63 & 3.91 & 2.50 & بيا الاتحادية \\
\hline
\end{tabular}

www.fao.org المصدر: جمعت وحسبت من قاعدة بيانات موقع منظمة الأغذية والزراعة 
r r أثر تفعيل الاتفاقيات التجارية على تغير حجم صادرات مصر من العنب

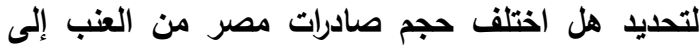
الاول التي ترتبط بها مصر بأي شكل من من أنشكال الاتفاقيات قبل تفعيل هذه الاتفاقية وبعدها فقل تم تطبيق اختبار (t) للفروق بين المتوسطين (قبل ويع الاتفاقية)

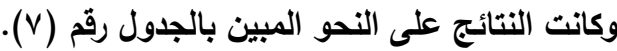

ويإجراء تحليل التباين أحادي الاتجاه لصادرات مصر

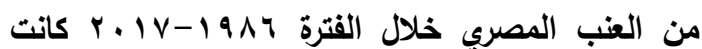

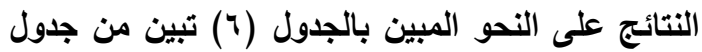
تحليل التباين ثبوت مغنوية الفروق بين الكميات المصدرة

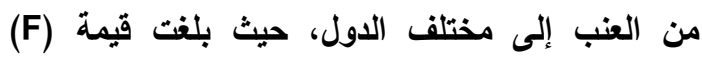

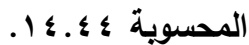

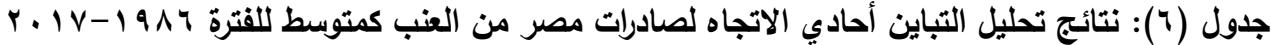

\begin{tabular}{|c|c|c|c|c|c|}
\hline المعنوية & F المحسوية F & متوسط مجموع المربعات & مجموع المربعات & درجات الحرية & مصدر التباين \\
\hline \multirow{3}{*}{0.000} & \multirow{3}{*}{14.44} & 163.87 & 1802.62 & 11 & بين الاول \\
\hline & & 11.35 & 4220.63 & 372 & داخل الدول \\
\hline & & & 6023.25 & 383 & الكلى \\
\hline
\end{tabular}

www.fao.org المصدر: جمعت وحسبت من قاعدة بيانات موقع منظمة الأغذية والزراعة

جدول (v): اختبار (t) لبيان أثر الاتفاقيات مع دول ترتبط بها مصر في اتفاقيات (قبل ويعد الاتفاقية) لصادرات مصر من

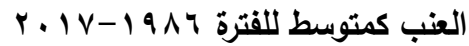

\begin{tabular}{|c|c|c|c|c|c|}
\hline المتوسط بعدة الاتفية & الاتفاقية قبل & قيمة(t) المحسوية & عداتد سنواتية ما بعد & عداتد سنواتية ما قبل & دول الاتفاقيات \\
\hline 14.93 & 1.22 & $\begin{array}{l}-13.56 * * \\
-12.25 * *\end{array}$ & 14 & 18 & إنجلترا \\
\hline 12.61 & 0.43 & $\begin{array}{l}-11.13 * * \\
-9.81 \% *\end{array}$ & 14 & 18 & هولندا \\
\hline 4.15 & 0.13 & $\begin{array}{l}-7.71 * * \\
-6.78 * *\end{array}$ & 14 & 18 & ألمانيا \\
\hline 2.59 & 0.02 & $\begin{array}{l}-8.51 \% * \\
-7.47 * *\end{array}$ & 14 & 18 & إيطاليا \\
\hline 1.27 & 0.24 & $\begin{array}{l}-4.05 * * \\
-3.76 * *\end{array}$ & 14 & 18 & بلجيكا \\
\hline 1.13 & 0.01 & $\begin{array}{l}-2.35 * * \\
-3.05 * *\end{array}$ & 20 & 12 & السعودية \\
\hline 1.43 & 0.00 & $\begin{array}{l}-2.84 * * \\
-2.49 * *\end{array}$ & 14 & 18 & سلوفانيا \\
\hline 1.08 & 0.000 & $\begin{array}{l}-1.95 * * \\
-2.53 * * \\
\end{array}$ & 20 & 12 & الإمارات \\
\hline 0.78 & 0.17 & $\begin{array}{l}-1.51 * * \\
-1.95 * *\end{array}$ & 20 & 12 & الكويت \\
\hline 1.13 & 0.15 & $\begin{array}{l}-6.77 * * \\
-6.30 * *\end{array}$ & 11 & 21 & النرويج \\
\hline 0.55 & 0.002 & $\begin{array}{l}-2.08 * * \\
-2.71 * *\end{array}$ & 20 & 12 & عمان \\
\hline
\end{tabular}

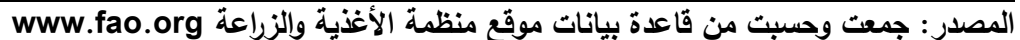
القيمة العليا في جدول (t) المحسوية بافتراض تجانس التباين والسفلي بافتراض عدم تجانس تجانس التباين، **-معنوي عند ا....، الأرقام بين الأقواس غير معنوية 
A. Awad, et al.,

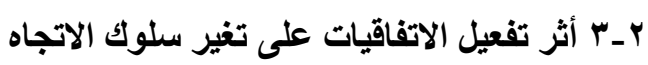

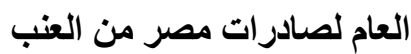

ويتقدير دالة الانحدار صادرات العب المصري للاول

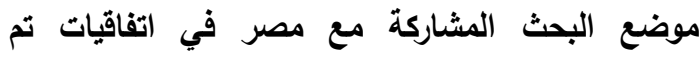
التوصل إلى الجدول (^). ويتبين من الجدول ثبوت مهندات

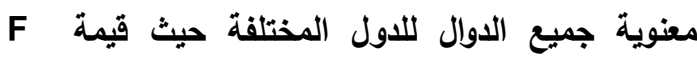

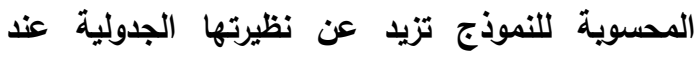

ويتبين ثبوت معنوية جيع الفروق بين متوسط الصادرات من العنب المصري بعد وقبل تفعيل الاتفاقيات

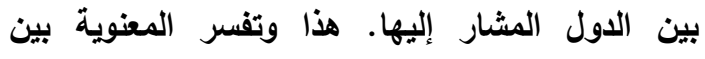
الفترتين من خلال زيادة متوسط الصادرات بشكل واضح من العب بعد تفعيل الاتفاقيات بين مصر ومجموعة

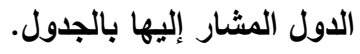

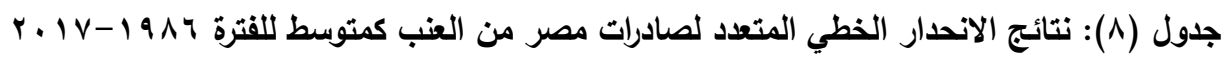

\begin{tabular}{|c|c|c|c|c|}
\hline F المحسوية F & $\hat{R}^{2}$ & $R^{2}$ & المعادلة & الدولة \\
\hline 66.25 & 0.86 & 0.88 & $\begin{aligned} y_{t}= & -0.9+0.22 x_{t}+12.01 D-0.07 D X_{t} \\
& (-0.7) \quad(1.8) \quad(2.5) \quad(-0.33)\end{aligned}$ & إنجلترا \\
\hline 221.97 & 0.96 & 0.96 & $\begin{aligned} y_{t}= & -0.5+0.09 x_{t}-12.04 D+0.9 D X_{t} \\
& (-0.64)(1.42) \quad(-4.7)\end{aligned}$ & هولندا \\
\hline 32.9 & 0.76 & 0.78 & $\begin{aligned} y_{t}= & -0.12+0.03 x_{t}-3.6 D+0.28 D X_{t} \\
& (-0.20) \quad(0.47) \quad(-1.64) \quad(2.7)\end{aligned}$ & ألمانيا \\
\hline 29.18 & 0.73 & 0.76 & $\begin{aligned} y_{t}= & -0.03+0.005 x_{t}-0.64 D+0.12 D X_{t} \\
(-0.07) & (0.14)\end{aligned}$ & إيطاليا \\
\hline 22.38 & 0.67 & 0.71 & $\begin{array}{r}y_{t}=-0.38+0.07 x_{t}+5.93 D-0.23 D X_{t} \\
(-1.53)\end{array}$ & بلجيكا \\
\hline 9.82 & 0.46 & 0.51 & $\begin{aligned} y_{t}= & .002+0.0 x_{t}-2.97 D+0.18 D X_{t} \\
& (0.0) \quad(0.0) \quad(-2.63)\end{aligned}$ & السعودية \\
\hline 27.32 & 0.72 & 0.75 & $\begin{array}{l}y_{t}=0+(3.82)^{-5} x_{t}-9.32 D+0.42 D X_{t} \\
\quad(0.0) \quad(0.001) \quad(-6.3)\end{array}$ & سلوفانيا \\
\hline 9.58 & 0.45 & 0.51 & $\begin{array}{c}y_{t}=(1.7)^{-15}-(1.35)^{-16} x_{t}-3.8 D+0.22 D X_{t} \\
(0.0) \quad(0.0)\end{array}$ & الإمارات \\
\hline 8.20 & 0.41 & 0.47 & 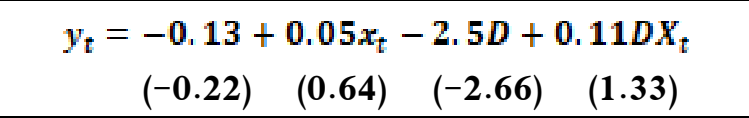 & الكويت \\
\hline 31.82 & 0.75 & 0.77 & $\begin{array}{r}y_{t}=-0.25+0.04 x_{t}+3.81 D-0.13 D X_{t} \\
(-1.8)\end{array}$ & النرويج \\
\hline 17.06 & 0.61 & 0.65 & $\begin{aligned} y_{t}= & 0.0+0.0 x_{t}-2.12 D+0.12 D X_{t} \\
& (0.0) \quad(0.0) \quad(-4.07) \quad(2.69)\end{aligned}$ & عمان \\
\hline
\end{tabular}

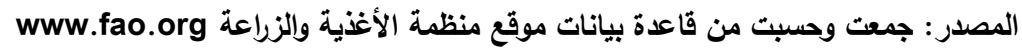

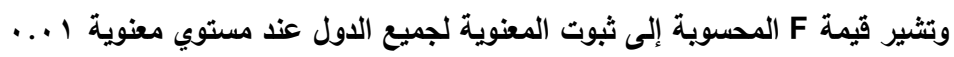


معنوية التغير في ميل الدالة حيث حلث تغير في الميل

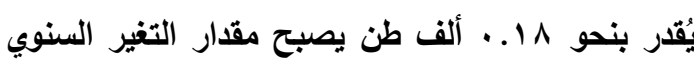

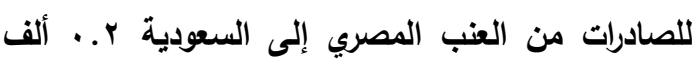
طن سنويا. ويالنسبة لاولة سلوفانيا فقد ثبتت معنوية

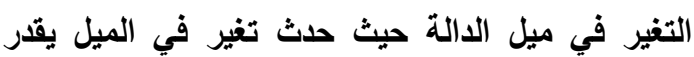
بنحو r\&.. ألف طن ليصبح مقدار التغير السنوي

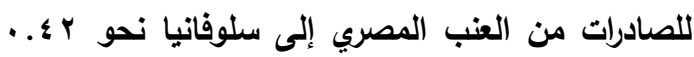
ألف طن سنويا. ويالنسبة للأمارات فقد كاتت مقدار التغير في ميل الدالة بنحو rr. . . ألف طن ليصبح مقدار التغير السنوي للصادرات من العنب المصري إلى الكويت

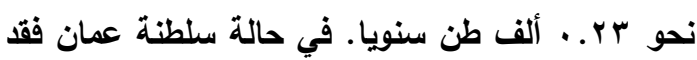

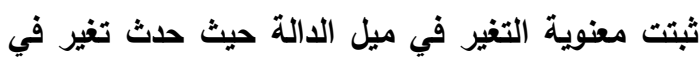
الميل يقدر بنحو r I. . ألف طن ليصبح مقار التغير السنوي للصادرات من العنب المصري إليها نحو با با..

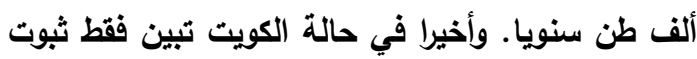

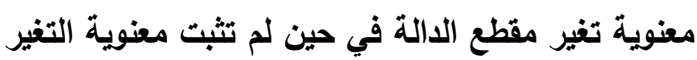

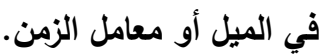

$$
\text { r-البطاطس }
$$

r-1 أثر وجود الاتفاقيات التجارية على حجم الصادرات من البطاطس المصري

تثير بيانات الجدول (9) أهم الدول المستوردة

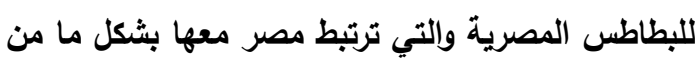
أشكال الاتفاقيات (تكتلات اقتصادية-|تفاقيات ثنائية) وتلك التي لا ترتبط بها مصر بأي اتفاقيات، حيث يتبين

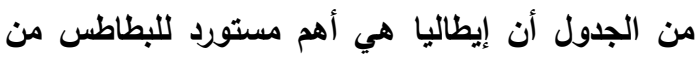
بين الدول ترتبط بها مصر من خلال الاتفاقيات التجارية،

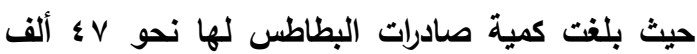

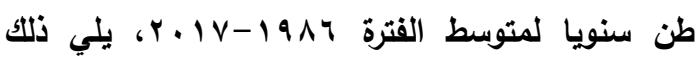
إنجلترا بنحو r أ ألف طن ثم اليونان ولبنان بصادرات تبلغ نحو لr و r r ألف طن في المتوسط لكل منها. أما بالنسبة لصادرات البطاطس إلى الدول خارج

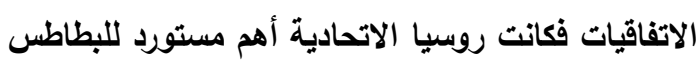
من مصر بكمية تصل إلى با ألف طن سنويا وإنحراف
أظهرت تقديرات معادلة الصادرات لإنجلترا ثبوت المتغير الانتقالي الدال علي وجود اتفاقيات من عدمه ومن ثم حدث تغير في مقطع الدالة في حين لم تثبت

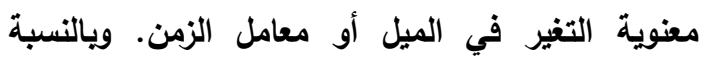

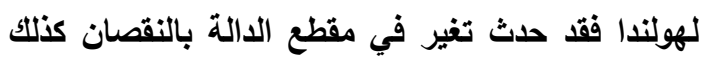

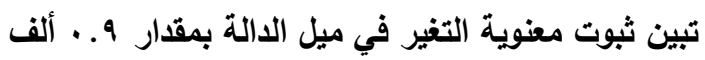

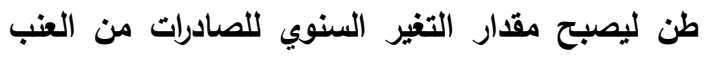

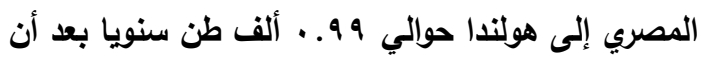
كان حوالي ا. . ألف طن قبل تفعيل الاتفاقية. وفي حالة ألمانيا وإيطاليا فقد تغير سلوك دالة الصادرات حيث ثبتت معنوية المتغير الذي يعكس تفاعل الزمن مع وجود الاتفاقيات من عدمها ويمعنى آخر فقد حدث تغير في ميل الدالة لكل منها بالزيادة ففي ألمانيا

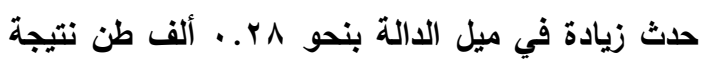
تطبيق الاتفاقية بين مصر ألمانيا ليصبح مقار التغير

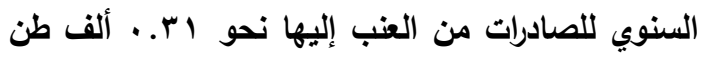
سنويا بعد أن كان حوالي ب... ألف طن قبل تفعيل الاتفاقية أما في حالة إيطاليا. فقد كان مقدار الزيادة في الميل بنحو rا...

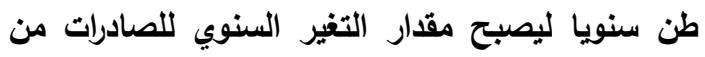

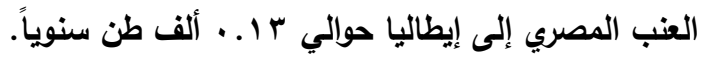
بالنسبة لدولتي بلجيكا والنرويج فقد أظهرت نتائج التقدير ثبوت معنوية تغير مقطع الدالة بالإضافة إلى ثبوت معنوية التغير في الميل ومعامل الزمن، ففي حالة بلجيكا

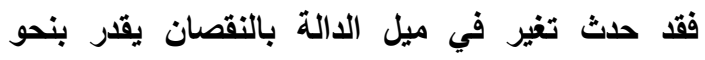
r r.. ألف طن ليصبح مقار التغير السنوي للصادرات

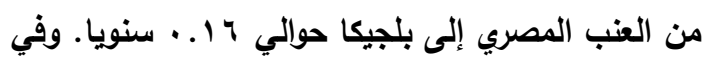

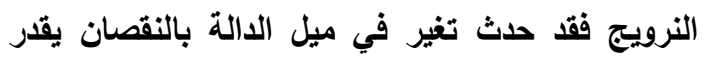

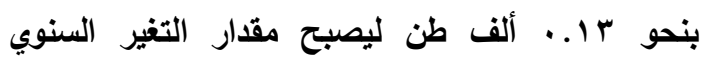
للصادرات من العنب المصري إلى النرويج نحو 9 ...

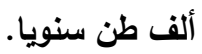
وفى حالة السعودية تبين ثبوت معنوية كل من

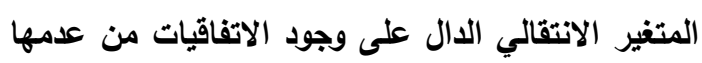
ومن ثم حدوث تغير في مقطع الدالة كذلك تبين ثبوت الاتفي 
A. Awad, et al.,

ويإجراء تحليل التباين أحادي الاتجاه لصادرات مصر

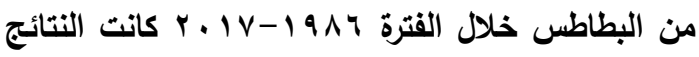

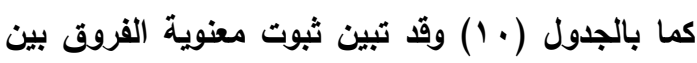

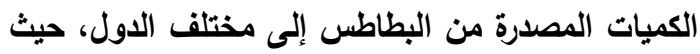

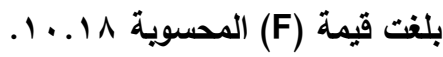

معياري يقدر بنحو 91 ألف طن في متوسط فترة البحث السابق إليها. ويحساب متوسط حجم الصادرات من البطاطس لمجموعة الدول التي ترتبط مصر معهاب

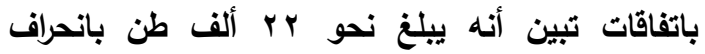

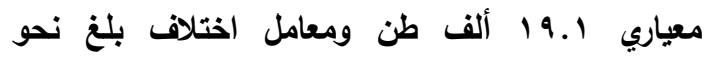

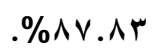

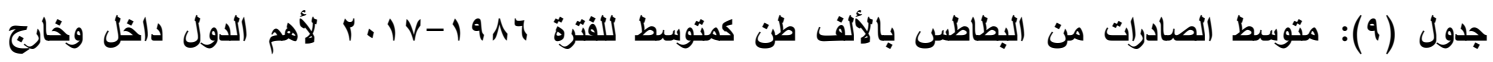

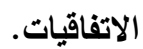

\begin{tabular}{|c|c|c|c|}
\hline \multicolumn{4}{|c|}{ دول الاتفاقيات } \\
\hline معامل الاختلاف (\%) & الانحراف المعياري & 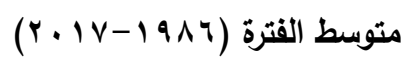 & 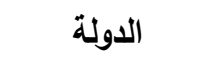 \\
\hline \multirow{10}{*}{87.83} & 38.96 & 46.81 & إيطاليا \\
\hline & 30.70 & 42.59 & إنجلترا \\
\hline & 24.48 & 37.14 & اليونان \\
\hline & 24.71 & 27.78 & 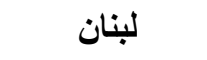 \\
\hline & 19.16 & 23.18 & ألمانيا \\
\hline & 12.02 & 5.16 & الإمارات \\
\hline & 9.14 & 4.94 & 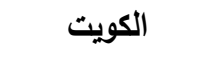 \\
\hline & 4.69 & 4.73 & هولندا \\
\hline & 7.87 & 3.21 & السعودية \\
\hline & 19.08 & 21.73 & المتوسط \\
\hline \multicolumn{4}{|c|}{ دول خارج الاتفاقيات } \\
\hline 157.9 & 97.8 & 61.9 & روسيا الاتحادية \\
\hline
\end{tabular}

المصدر: جمعت وحسبت من قاعدة بيانات موقع منظمة الأغذية والزراعة

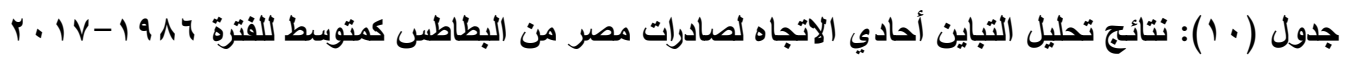

\begin{tabular}{|c|c|c|c|c|c|}
\hline المعنوية & المحسوية F & متوسط مجموع المريعات & مجموع المريعات & درجات الحرية & مصدر التباين \\
\hline \multirow{3}{*}{0.000} & \multirow{3}{*}{10.18} & 14156.91 & 127412.19 & 9 & بين الدول \\
\hline & & 1390.56 & 431073.05 & 310 & داخل الاول \\
\hline & & & 558485.24 & 319 & الكلي \\
\hline
\end{tabular}

www.fao.org المصدر: جمعت وحسبت من قاعدة بيانات موقع منظمة الأغذية والززاعة 
ويلاحظ من الجدول ثبوت معنوية جميع الفروق بين متوسط الصادرات من البطاطس بعد وقبل تفعيل الاتفاقيات بين الدول المشار إليها بالجدول السابق فيما عدا دولتي اليونان وألمانيا والذي يمكن تفسيره من خلال حجم التغير في الصادرات بين الفترتين. هذا وتفسر المعنوية بين الفترتين من خلال زيادة متوسط الصادرات

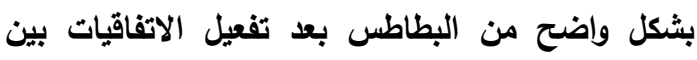
مصر ومجموعة الدول المشار إليها بالجدول. r-r أثر تفعيل الاتفاقيات التجارية على تغير حجم الصادرات من البطاطس المصري جاءت نتائج تطبيق اختبار (t) للفروق بين المتوسطين (قبل ويعد الاتفاقية) لصادرات مصر من لناعن البطاطس للاول التي ترتبط بها مصر في اتفاقيات على

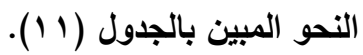

جدول (1 1): اختبار (t) لبيان أثر الاتفاقيات مع دول ترتبط بها مصر في اتفاقيات (قبل ويعد الاتفاقية) صادرات مصر من

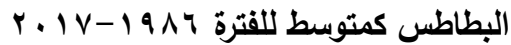

\begin{tabular}{|c|c|c|c|c|c|}
\hline الاتواقيط بعد & الاتواقيط قبل & قيمة(t) المحسوية & عدد سنوات ما بعد & عدد سنوات ما قبل & الاتفاقيات \\
\hline 80.59 & 20.53 & $\begin{array}{l}-6.76^{* *} \\
-7.23^{* *}\end{array}$ & 14 & 18 & إيطاليا \\
\hline 16.85 & 62.60 & $\begin{array}{l}6.23^{* * *} \\
6.98 * *\end{array}$ & 14 & 18 & إنجلترا \\
\hline 55.13 & 23.14 & $\begin{array}{l}(-4.79) \\
(-4.98)\end{array}$ & 14 & 18 & اليونان \\
\hline 43.14 & 2.16 & $\begin{array}{l}-7.73^{* *} \\
-9.23^{* *}\end{array}$ & 20 & 12 & ل لبنان \\
\hline 20.39 & 25.35 & $\begin{array}{l}(0.72) \\
(0.77)\end{array}$ & 14 & 18 & ألمانيا \\
\hline 8.25 & 0.00 & $\begin{array}{l}-1.97^{* *} \\
-2.55^{* *} \\
\end{array}$ & 20 & 12 & الإمارات \\
\hline 6.80 & 1.85 & $\begin{array}{l}-1.51 * * \\
-1.94 * *\end{array}$ & 20 & 12 & الكويت \\
\hline 7.33 & 2.71 & $\begin{array}{l}-3.13^{* *} \\
-2.97^{* *}\end{array}$ & 14 & 18 & هولندا \\
\hline 0.53 & 7.69 & $\begin{array}{l}2.74 * * \\
2.11 * *\end{array}$ & 20 & 12 & السعودية \\
\hline
\end{tabular}

www.fao.org المصدر : جمت وحسبت من قاعدة بيانات موقع منظمة الأغذية والزراعة القيمة العليا في جدول (t) المحسوية بافتراض تجانس التباين والسفلي بافتراض عدم تجانس التباين ** *-مغنوي عند ا.... الأرقام بين الأقواس غير معنوية جلول 
ويالنسبة لإنجلترا لم تثبت مغنوية المتغير الانتقالي الدال

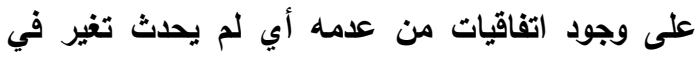
مقطع الدالة وكذلك لم تثبت معنوية المتغير الذي يعكس الثس تفاعل الزمن مع وجود الاتفاقيات من عدمها ويمعنى آخر لم يحدث تغير في ميل الدالة. كما تثبير التقديرات إلى ثبوت مغنوية المتغير الانتقالي الدال على وجود اتفاقيات من عدمه ومن ثم حدوث تغير في مقطع الدالة لكل من دولة اليونان ودولة الكويت ودولة الإمارات. وفي في في

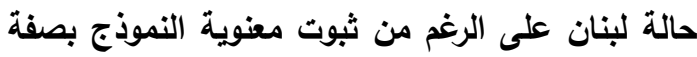
عامة إلا انه لم تثبت معنوية أي من المتغيرات الثلاث.

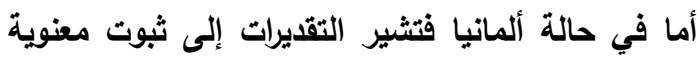
التغير في ميل الدالة حيث حدث تغير في الميل بالنقصان قدر بنحو r.r ألف طن ليصبح مقدار التغير السنوي في في الصادرات من البطاطس إلى ألمانيا حوالي V. . . ألف طن

سنويا. r-r أثر تفعيل الاتفاقيات على تغير سلوك الاتجاه العام لصادرات مصر من البطاطس تم تقدير دالة انحدار صادرات البطاطس باستخدام البيانات المتاحة عن صادرات مصر من البطاطس للاول موضع البحث المشاركة مع مصر في اتفاقيات وتم

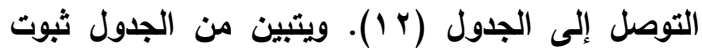

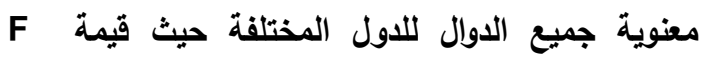
المحسوية للنموذج تزيد عن نظيرتها الجدولية عند مستوى معنوية ال.... كما أظهرت تقديرات معادلة

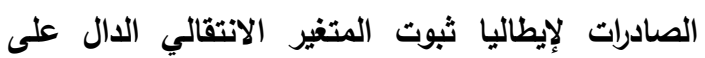
وجود اتفاقيات من عدمه ومن ثم حدث تغير في مقطع الالة بالإضافة إلى ثبوت معنوية التغير في ميل الدالة بالنقصان يقار بحوالي V.r ألف طن ليصبح مقاري

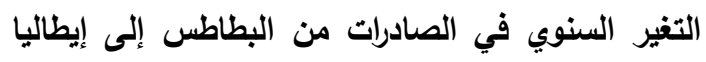

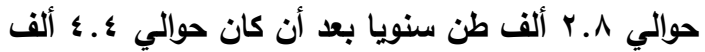
طن قبل تفعيل الاتفاقية. كما ثبتت معنوية معامل الزمن.

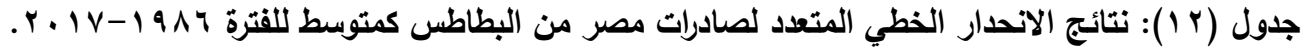

\begin{tabular}{|c|c|c|c|c|}
\hline F المحسوية & $\boldsymbol{R}^{2}$ & $R^{2}$ & المعادلة & الدولة \\
\hline 48.57 & 0.82 & 0.84 & $\begin{array}{l}y_{t}=-20.8+4.43 x_{t}+175.04 D-7.2 D X_{t} \\
(-2.6) \quad(5.8) \quad(8.97) \quad(-5.5)\end{array}$ & إيطاليا \\
\hline 29.94 & 0.74 & 0.76 & $\begin{array}{l}y_{t}=94.8-3.4 x_{t}-52.97 D+2.4 D X_{t} \\
(12.2)(-4.7) \quad(-1.9)\end{array}$ & إنجلترا \\
\hline 10.28 & 0.47 & 0.52 & $\begin{array}{l}y_{t}=5.8+1.8 x_{t}+62.6 D-2.3 D X_{t} \\
(0.7)(2.3) \quad(1.97) \quad(-1.6)\end{array}$ & اليونان \\
\hline 22.00 & 0.67 & 0.70 & 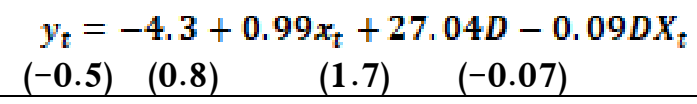 & لبنان \\
\hline 4.48 & 0.25 & 0.32 & \begin{tabular}{l}
\multicolumn{4}{l}{$y_{t}=0.22+2.6 x_{t}+37.5 D-3.3 D X_{t}$} \\
$(0.03) \quad(3.5) \quad(1.3) \quad(-2.5)$
\end{tabular} & ألمانيا \\
\hline 7.20 & 0.38 & 0.44 & $\begin{array}{c}y_{t}=1.8-3.03 x_{t}-24.9 D+1.5 D X_{t} \\
(0.0) \quad(0.0) \quad(-2.4)\end{array}$ & الإمارات \\
\hline 6.81 & 0.36 & 0.42 & $\begin{array}{l}y_{t}=-0.48+0.3 x_{t}-18.6 D+0.8 D X_{t} \\
(-0.12) \quad(0.59) \quad(-2.4) \quad(1.18)\end{array}$ & الكويت \\
\hline 9.25 & 0.44 & 0.50 & $\begin{array}{l}y_{t}=0.84+0.27 x_{t}+26.9 D-1.05 D X_{t} \\
(0.05) \quad(1.7) \quad(4.3) \quad(-3.7)\end{array}$ & هولتدا \\
\hline 17.89 & 0.62 & 0.66 & $\begin{array}{l}y_{t}=23.8-2.5 x_{t}-24.1 D+2.5 D X_{t} \\
(7.96)(-6.1) \quad(-4.6) \quad(5.6)\end{array}$ & السعودية \\
\hline
\end{tabular}

المصدر: جمعت وحسبت من قاعدة بيانات موقع منظمة الأغذية والزراعة، تثبير قيمة F المحسوية إلى ثبوت المعنوية لجميع الدول 
مستورد للبصل من بين الدول ترتبط بها مصر من خلال الاتفاقيات التجارية، حيث بلغت كمية صادرات البصل لها

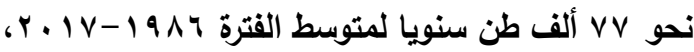
يلي ذلك هولتنا بنحو 9 ألف طن ثم لبنان والولايات المتحدة بصادرات تبلغ نحو 1.7 وم ألف طن في المتوسط لكل منها.

أما بالنسبة لصادرات البصل إلى الدول خارج الاتفاقيات فكاتت روسيا الاتحادية أهم مستورد للبصل من مصر بكمية تصل إلى حوالي rv ألف طن سنوياً وانحراف معياري يقدر بنحو ع ب ألف طن في متوسط فترة البحث السابق الإشارة إليها. ويحساب متوسط حجم الصادرات من البصل لمجموعة الاول التي ترتبط مصر معها باتفاقات تبين أنه بيلغ نحو با ألف طن بانحراف معياري 10 ألف طن ومعامل اختلاف بلغ نحو .\%119.1
ويالنسبة لاولة هولتدا فقد أظهرث التقديرات ثبوت معنوية كل من المتغير الانتقالي الدال على وجود الاتفاقيات من عدمها ومن ثم حدوث تغير في مقطع الدالة كذلك تبين ثبوت معنوية التغير في ميل الدالة حيث حدث تغير في الميل بالنقصان يُقدر بنحو 1.1 ألف طن ليصبح مقدار التغير السنوي للصادرات من البطاطس إلى هولندا حوالي r. ألف طن سنويا. وأخيرا في حالة السعودية فقد حدث تغير في مقطع الدالة بالنقصان إلا هوي أن ميل الدالة حدث فيه تغير بالزيادة بنحو ه.r ألف طن

$$
\text { ع - - البصل }
$$

ع ـ أثر وجود الاتفاقيات التجارية على حجم الصادر ات مصر من البصل وجود الانيات وتوضح بيانات الجدول (r I ) أهم الاول المستوردة للبصل المصري، حيث يتبين أن السعودية هي أهم

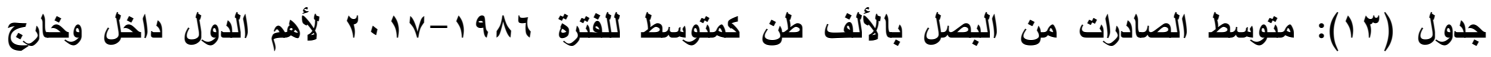
الاتفاقيات.

\begin{tabular}{|c|c|c|c|}
\hline \multicolumn{4}{|c|}{ دول الاتفاقيات } \\
\hline معامل الاختلاف(\%) & الانحراف المعياري & 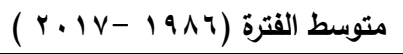 & 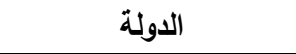 \\
\hline \multirow{11}{*}{119.8} & 81.3 & 77.0 & السعودية \\
\hline & 12.6 & 9.1 & هولندا \\
\hline & 7.1 & 8.6 & 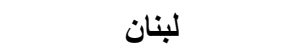 \\
\hline & 8.5 & 8.1 & الولايات المتحدة الأمريكية \\
\hline & 9.6 & 6.6 & الكويت \\
\hline & 8.9 & 4.7 & 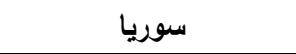 \\
\hline & 12.1 & 3.8 & 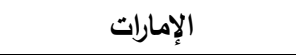 \\
\hline & 4.4 & 3.6 & 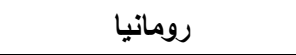 \\
\hline & 3.6 & 3.4 & 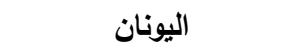 \\
\hline & 5.1 & 3.2 & 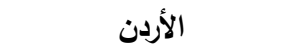 \\
\hline & 15.3 & 12.8 & المتوسط \\
\hline \multicolumn{4}{|c|}{ دول خارج الاتفاقيات } \\
\hline 123.4 & 33.6 & 27.2 & روسيا الاتحادية \\
\hline
\end{tabular}

www.fao.org المصدر: جمعت وحسبت من قاعدة بيانات موقع منظمة الأغذية والزراعة 
F معنوية جميع الدوال للاول المختلفة حيث قيمة

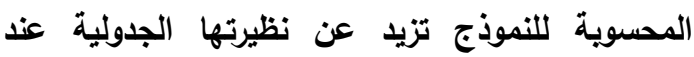

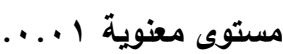

وعلى الرغم من ثبوت معنوية النموذج بصفة عامة إلا أن بعض الدول لم تثبت معنويتها قبل أو بعد تفعيل الاتفاقيات كما هو الحال في السعودية والكويت وسوريا

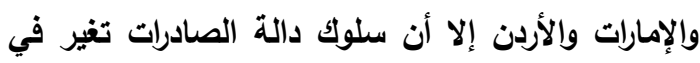
حالة هولندا فقد ثبتت معنوية كل من المتغير الانتقالي الدال على وجود الاتفاقيات من عدمها ومن ثم حدوث تغير في مقطع الدالة كذلك تبين ثبوت معنوية التغير في

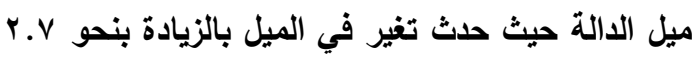
ألف طن ليصبح مقدار التغير السنوي للصادرات من البصل إلى هولندا حوالي • •. ألف طن سنويا. وفي حالة لبنان فقد أظهرت النتائج ثبوت معنوية مقطع الدالة بالزيادة إلا أن ميل الدالة حدث فيه تغير بالنقصان بنحو VV. . ألف طن سنويا ليصبح مقدار التغير السنوي للصادرات من البصل إلى لبنان حوالي rr.. ألف طن سنوياً. أما بالنسبة للولايات المتحدة

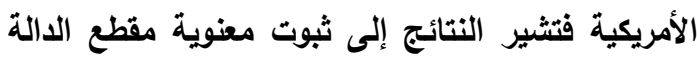
بالنقصان وكذلك ثبوت معنوية التغير في ميل الدالة حيث

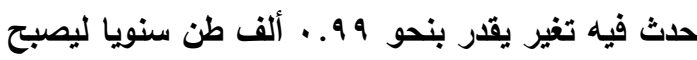
مقدار التغير السنوي للصادرات من البصل إلى الولايات

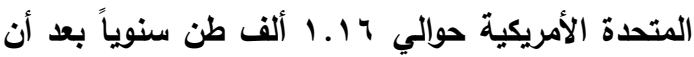
كان حوالي V I . . ألف طن قبل تفعيل الاتفاقية
ويإجراء تحليل التباين أحادي الاتجاه لصادرات مصر

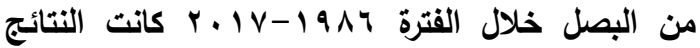
على النحو المبين بالجدول (؛ 1) تبين من جدول تحليل التباين ثبوت معنوية الفروق بين الكميات المصدرة من البصل إلى مختلف الدول، حيث بلغت قيمة (F)

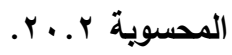

ع - r أثر تفعيل الاتفاقيات التجارية على تغير حجم صادرات مصر من البصل

ويتطبيق اختبار (t) للفروق بين المتوسطين (قبل ويعد الاتفاقية) كانت النتائج على النحو المبين بالجدول

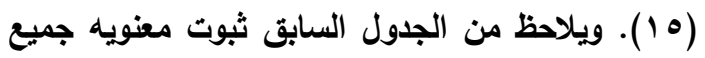
الفروق بين متوسط الصادرات من البصل بعد وقبل تفعيل

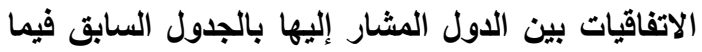
عدا دولتي الكويت واليونان والذي يمكن تفسيره من خلال

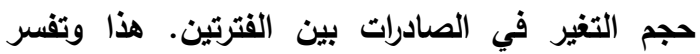
المغنوية بين الفترتين من خلال زيادة متوسط الصادرات بشكل واضح من البصل بعد تفعيل الاتفاقيات بين مصر ملئر ومجموعة الاول المشار إليها بالجدول.

צ - أثر تفعيل الاتفاقيات على تغير سلوك الاتجاه العام لصادرات مصر من البصل وياستخدام البيانات المتاحة عن صادرات مصر من فن

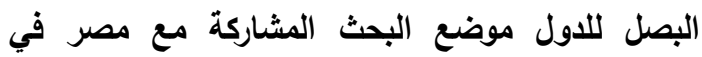
اتفاقيات تم التوصل إلى دوال اتحار صادرات البصل المصري كما بالجدول († 1). ويتبين من الجدول ثبوت

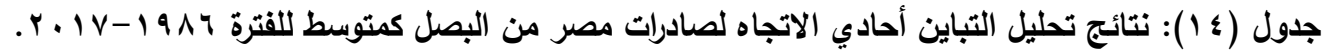

\begin{tabular}{|c|c|c|c|c|c|}
\hline المعنوية & F المحسوية F & متوسط مجموع المربعات & مجموع المربعات & درجات الحرية & مصدر التباين \\
\hline \multirow{3}{*}{0.000} & \multirow{3}{*}{20.2} & 15409.5 & 145095.3 & 10 & بين الدول \\
\hline & & 763.44 & 260335.7 & 341 & داخل الدول \\
\hline & & & 414431.0 & 351 & الكلي \\
\hline
\end{tabular}

المصدر: المصدر: جمعت وحسبت من قاعدة بيانات موقع منظمة الأغذية والزراعة www.fao.org 
جدول (ه 1): اختبار (t) لبيان أثر الاتفاقيات مع دول ترتبط بها مصر في اتفاقيات (قبل ويعد الاتفاقية) لصادرات مصر

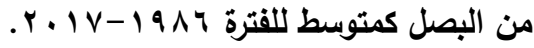

\begin{tabular}{|c|c|c|c|c|c|}
\hline الاتفاقيط بعد & الاتتفاقية قبل & قيمة (t) المحسوية & عدد سنوات ما بعد & عداتلفاقية ما قبل & دول الاتفاقيات \\
\hline 121.47 & 2.86 & $\begin{array}{l}-5.64 * * \\
-7.30 * *\end{array}$ & 20 & 12 & السعودية \\
\hline 20.26 & 0.40 & $\begin{array}{l}-7.12^{* *} \\
-6.26^{* *}\end{array}$ & 14 & 18 & هولندا \\
\hline 13.02 & 1.16 & $\begin{array}{l}-7.75^{* *} \\
-7.87^{* *}\end{array}$ & 20 & 12 & لبنان \\
\hline 15.4 & 0.58 & $\begin{array}{l}-9.5^{* *} \\
-9.5^{* *}\end{array}$ & 16 & 16 & الولايات المتحدة \\
\hline 8.00 & 4.27 & $\begin{array}{l}(-1.07) \\
(-1.26)\end{array}$ & 20 & 12 & الكويت \\
\hline 7.52 & 0.00 & $\begin{array}{l}-2.49^{* *} \\
-3.23^{* *}\end{array}$ & 20 & 12 & سوريا \\
\hline 6.04 & 0.00 & $\begin{array}{l}-1.34^{* *} \\
-1.80^{* *}\end{array}$ & 20 & 12 & الإمارات \\
\hline 6.08 & 1.68 & $\begin{array}{l}-3.18^{* *} \\
-3.06^{* *}\end{array}$ & 20 & 12 & رومانيا \\
\hline 2.62 & 3.97 & $\begin{array}{l}(1.05) \\
(1.11)\end{array}$ & 14 & 18 & اليونان \\
\hline 5.01 & 0.09 & $\begin{array}{l}-2.9 * * \\
-3.81 * *\end{array}$ & 20 & 12 & الأردن \\
\hline
\end{tabular}

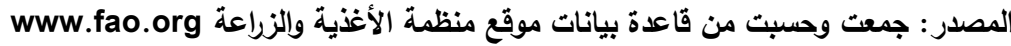

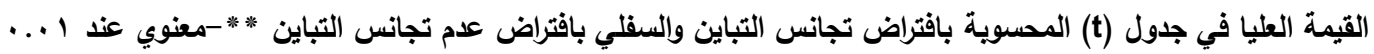
الأرقام بين الأقواس غير معنوية جلية 
A. Awad, et al.,

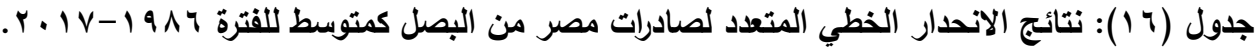

\begin{tabular}{|c|c|c|c|c|}
\hline 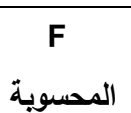 & $\boldsymbol{R}^{2}$ & $R^{2}$ & المعادلة & الدولة \\
\hline 13.48 & 0.55 & 0.59 & $\begin{array}{c}y_{t}=7.94-0.78 x_{t}+4.8 D+5.6 D X_{t} \\
(0.24) \quad(-0.7) \quad(0.08)\end{array}$ & السعودية \\
\hline 317.63 & 0.97 & 0.97 & 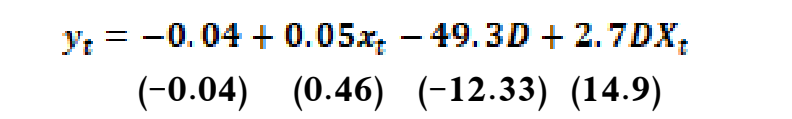 & هولتدا \\
\hline 32.38 & 0.69 & 0.72 & $\begin{array}{c}y_{t}=-2.3+0.54 x_{t}+20.65 D-0.77 D X_{t} \\
(-0.94) \quad(1.6) \quad(4.7)\end{array}$ & لبنان \\
\hline 229.5 & 0.96 & 0.96 & $\begin{array}{c}y_{t}=-0.62+0.17 x_{t}-12.41 D+0.99 D X_{t} \\
(-.66)\end{array}$ & الولايات المتحدة \\
\hline 2.75 & 0.15 & 0.23 & $\begin{array}{c}y_{t}=-4.16+1.3 x_{t}-3.0 D-0.62 D X_{t} \\
(-.76) \quad(1.8) \quad(-0.31) \quad(-0.76)\end{array}$ & الكويت \\
\hline 2.03 & 0.09 & 0.18 & $\begin{array}{c}y_{t}=(-3.1)^{-14}+4.3^{-15} x_{t}+11.3 D-0.17 D X_{t} \\
(0.0)\end{array}$ & سوريا \\
\hline 3.44 & 0.19 & 0.27 & $\begin{array}{ccc}y_{t}=(-2.3)^{-14}+(4.6)^{-15} x_{t}-20.8+1.2 D X_{t} \\
(0.0) & (0.0) & (-1.75)\end{array}$ & الإمارات \\
\hline 6.2 & 0.34 & 0.41 & $\begin{aligned} y_{t}= & -1.39+0.33 x_{t}+17.45 D-0.72 D X_{t} \\
(-0.79) & (2.02)\end{aligned}$ & رومانيا \\
\hline 19.7 & 0.64 & 0.68 & $\begin{aligned} y_{t}= & -2.59+0.69 x_{t}+14.68 D-1.06 D X_{t} \\
(-2.43) & (7.02)\end{aligned}$ & اليونان \\
\hline 2.83 & 0.15 & 0.23 & $\begin{aligned} y_{t}= & 0.21-0.02 x_{t}+2.32 D+0.13 D X_{t} \\
& (0.07)(-0.05)\end{aligned}$ & الأردن \\
\hline
\end{tabular}

www.fao.org المصدر: جمعت وحسبت من قاعدة بيانات موقع منظمة الأغذية والزراعة

ويالنسبة لرومانيا فقد أظهرت التقبيرات ثبوت المتغير

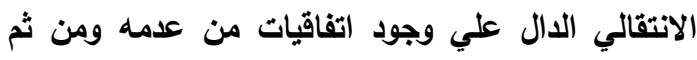

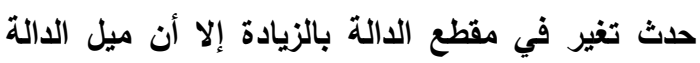

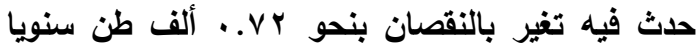
ليصبح مقار التغير السنوي للصادرات من البصل إلى بلى

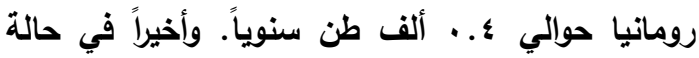

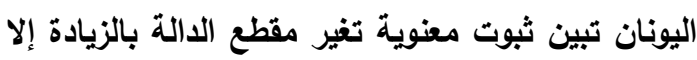

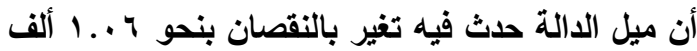
طن سنويا ليصبح مقدار التغير السنوي للصادرات من بن التيرن المراجع 1) كامل بكري، "التكامل الاقتصادي" الإسكندرية، مطبعة المكتب العربي الحديث الكري، الكامل الاعل

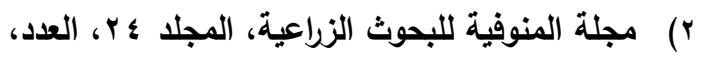
فبراير 1999

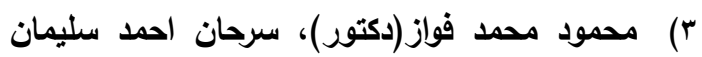
(دكتور):" التجارة الخارجية البينية الكلية والزراعية

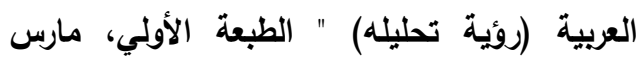
البصل إلى رومانيا حوالي ا. . ألف طن سنوياً. 
Impact of the Egyptian partnership in economic blocs and bilateral

؛) مقروس كمال، "دور المشروعات المشتركة في

4) نثرات إحصاءات التجارة الخارجية للصادرات

تحقيق التكامل الاقتصادي: دراسة مقارنة بين

والواردات الزراعية، وزارة الزراعة واستصلاح

التجربة الأوروبية والتجرية المغاريبة"، أطروحة

الأراضي، قطاع الثئون الاقتصادية، أعداد متفرقة

ماجستير، كلية العلوم الاقتصادية والعلوم التجارية

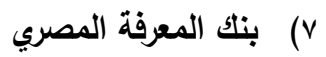

وعلوم التيسير، جامعة فرحات عباس، الجزائر

r. Ir

8) G.M.K. MADNANI "Introduction to econometrics principles and applications" University of Udaipur

•) موقع منظمة الأغذية والزراعة على الثبكة الدولية

للمطلومات، www.fao.org 
A. Awad, et al.,

\title{
IMPACT OF THE EGYPTIAN PARTNERSHIP IN ECONOMIC BLOCS AND BILATERAL AGREEMENTS ON Egypt's AGRICULTURAL EXPORTS
}

\author{
A. Awad, M. Elgendy, R. M. A. Zein and Hager M. Kandil \\ Dept. of Agricultural Economics and Agri-business Faculty of Agriculture-Menoufia \\ University.
}

\begin{abstract}
The study aimed to answer three questions, the first of which looks at the difference in the volume of Egyptian agricultural exports between countries that enter into economic or bilateral blocs with Egypt from their counterparts that do not share with Egypt. The results were as follows: The average volume of Egypt's exports of oranges, grapes, potatoes, and onions to the countries with which Egypt has agreements reached about 26, 2, 22, 13 thousand tons as an average for the period 1986-2017, respectively. While the average volume of exports of the same crops to countries with which Egypt is not bound by any form of agreements was about 27, 2.5, 62, 27 thousand tons during the same period. The significant differences between the quantities exported of the four crops to different countries were also proven.

Moving to the second question, which reflects the effect of activating trade agreements or blocs on the change in the volume of exports of the study crops, the results were as follows: The results of the t-test for the differences between the two averages before and after the agreement showed that all the differences between the average exports of Egyptian oranges after and before activating the agreements between the countries referred to in the research were significant, except for Jordan and Kuwait. In the case of the grape crop, the results showed that all the differences between the average exports of Egyptian grapes were insignificant after and before activating the agreements. All the differences between average exports of potatoes after and before activating the agreements between the aforementioned countries, with the exception of Greece and Germany, were also found to be significant. Finally, regarding the onion crop, the results indicated that all the differences between the average exports of Egyptian onions after and before activating the agreements from the countries referred to in the study were significant, except for the countries of Kuwait and Greece. Finally, regarding the third question, which examines the effect of activating the agreements on the behavior of agricultural exports to the countries participating with Egypt in trade agreements only, it shows that the regression function model is significant in general for the four crops, regardless that this significance was in the function segment only or the slope only or both together.
\end{abstract}

Key words: Foreign trade, economic blocs, agricultural exports, bilateral agreements.

$$
\begin{aligned}
& \text { أسماء السادة المحكمين } \\
& \text { أ.د/ محمد محمد حافظ الماحى كلية الزراعة - الثاطبى - جامعة الأسكندرية }
\end{aligned}
$$

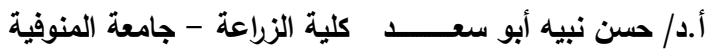


Impact of the Egyptian partnership in economic blocs and bilateral 